\title{
Arginine improves peroxisome functioning in cells from patients with a mild peroxisome biogenesis disorder
}

Kevin Berendse ${ }^{1,2}$, Merel S Ebberink', Lodewijk IJIst ${ }^{1}$, Bwee Tien Poll-The², Ronald J A Wanders ${ }^{1}$ and Hans R Waterham ${ }^{1 *}$

\begin{abstract}
Background: Zellweger spectrum disorders (ZSDs) are multisystem genetic disorders caused by a lack of functional peroxisomes, due to mutations in one of the PEX genes, encoding proteins involved in peroxisome biogenesis. The phenotypic spectrum of ZSDs ranges from an early lethal form to much milder presentations. In cultured skin fibroblasts from mildly affected patients, peroxisome biogenesis can be partially impaired which results in a mosaic catalase immunofluorescence pattern. This peroxisomal mosaicism has been described for specific missense mutations in various PEX genes. In cell lines displaying peroxisomal mosaicism, peroxisome biogenesis can be improved when these are cultured at $30^{\circ} \mathrm{C}$. This suggests that these missense mutations affect the folding and/or stability of the encoded protein. We have studied if the function of mutant PEX1, PEX6 and PEX12 can be improved by promoting protein folding using the chemical chaperone arginine.
\end{abstract}

Methods: Fibroblasts from three PEX1 patients, one PEX6 and one PEX12 patient were cultured in the presence of different concentrations of arginine. To determine the effect on peroxisome biogenesis we studied the following parameters: number of peroxisome-positive cells, levels of PEX1 protein and processed thiolase, and the capacity to $\beta$-oxidize very long chain fatty acids and pristanic acid.

Results: Peroxisome biogenesis and function in fibroblasts with mild missense mutations in PEX1, 6 and 12 can be improved by arginine.

Conclusion: Arginine may be an interesting compound to promote peroxisome function in patients with a mild peroxisome biogenesis disorder.

Keywords: Peroxisome biogenesis disorder, Zellweger spectrum disorder, Misfolded protein, Peroxisomal mosaicism, Arginine, Therapy

\section{Background}

Peroxisomes are ubiquitous organelles bound by a single membrane and present in nearly all eukaryotic cells. There are approximately 50 different peroxisomal enzyme proteins, which are involved in various biochemical pathways and can be present in different types of cells. Among others, peroxisomes are involved in the degradation of Very Long Chain Fatty Acids (VLCFA; $\geq \mathrm{C}_{22}:_{0}$ ), the formation

\footnotetext{
* Correspondence: h.r.waterham@amc.uva.nl

'Department of Clinical Chemistry, Laboratory Genetic Metabolic Diseases, Academic Medical Center, University Hospital of Amsterdam, Meibergdreef 9, 1105 AZ Amsterdam, The Netherlands

Full list of author information is available at the end of the article
}

of bile acids, the synthesis of plasmalogens and the oxidation of phytanic acid [1]. Peroxisome biogenesis disorders (PBDs) are autosomal recessive disorders characterized by an impairment in one or more peroxisomal functions. The PBDs can be divided into two subtypes; the Zellweger Spectrum Disorders (ZSD, OMIM \#601539) and rhizomelic chondrodysplasia punctata type I (RCDP, OMIM \#215100). Clinically and biochemically, the ZSD represent a continuum of at least three phenotypes, including Zellweger syndrome (ZS, OMIM \#214100) as the most severe, neonatal adrenoleukodystrophy (NALD, OMIM \#202370), and infantile Refsum disease (IRD, OMIM \# 266510) [2-4] as the least severe phenotype.

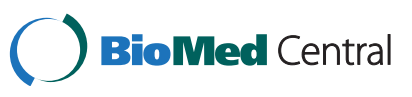


In $\mathrm{ZS}$, there is a complete loss of peroxisomal functions. In contrast, cells from NALD and IRD patients still contain functional peroxisomes albeit reduced in number. When skin fibroblasts from milder patients are cultured at $37^{\circ} \mathrm{C}$ and then examined for the localization of the peroxisomal matrix protein catalase, a mixed population of cells with either catalase-containing or catalase-lacking peroxisomes can be seen [5-7]. This phenomenon is called peroxisomal mosaicism and has been described for mutations in various $P E X$ genes (e.g. PEX1, $P E X 2$, PEX6, PEX10 and PEX12), which are associated with a relatively mild phenotype $[5,6,8,9]$.

Proteins encoded by $P E X$ genes are called peroxins and play a role in normal peroxisome assembly. Currently 14 peroxins are known to be involved in this process and mutations in 13 of the PEX genes have been associated with ZSDs $[9,10]$. When skin fibroblasts, displaying peroxisomal mosaicism, are cultured at $30^{\circ} \mathrm{C}$, all cells regain catalase-containing peroxisomes. In contrast, when the fibroblasts are cultured at $40^{\circ} \mathrm{C}$, all cells lose catalasecontaining peroxisomes [5] which resembles the peroxisomal phenotype in fibroblasts from classical Zellweger patients. This suggests that the mutations associated with peroxisomal mosaicism cause an unstable and/or incorrectly folded PEX protein. Moreover, these observations also suggest that improving the folding of the mutated protein, e.g. by lowering the temperature, can result in the restoration of peroxisome biogenesis. Here, we have studied whether the chemical chaperone arginine is also capable of improving peroxisome biogenesis in fibroblasts displaying peroxisomal mosaicism.

Chemical chaperones are small-molecule osmolytes, which have the capacity to improve protein folding. Previous studies have shown that several compounds are capable of improving peroxisomal function [11]. Arginine has been described to correct protein folding and suppress protein aggregation in vitro [12]. Furthermore, it has been shown that arginine supplementation restored PDHc function in a patient with pyruvate dehydrogenase deficiency [13]. The mechanism which underlies its chaperone function is unknown, but might involve conformational correction and prevention of nonproductive protein interactions [14].

In this study, we show that arginine is able to improve peroxisome biogenesis and functioning in cells from patients with a mild ZSD, that display peroxisomal mosaicism due to mild mutations in the PEX1, PEX6 or PEX12 gene.

\section{Material and methods \\ Cell culture}

For this study we used primary skin fibroblasts from different patients with a mild peroxisomal disease. Three cell lines were homozygous for the c.2528G>A (p.G843D) mutation in the PEX1 gene (PEX1-G843D); one cell line was compound heterozygous for the c.821C>T (p.P274L) and c.1314_1321delGGAGGCCT (p.E439fsX3) mutation in PEX6 and one cell line was homozygous for the c.959C>T (p.S320F) mutation in the PEX12 gene. As negative control we used a cell line homozygous for the c.2097insT (p.I700fsX41) mutation in PEX1 (PEX1I700fsX41), which has no functional peroxisomes (Zellweger syndrome). In accordance with the institutional guidelines and the Dutch Code of Conduct, identifiable clinical and personal data from the patients were not available for this study. The cell lines were cultured in 10\% Dulbecco's Modified Eagle's Medium (DMEM) supplemented with $10 \%$ fetal bovine serum, $25 \mathrm{mM}$ HEPES buffer, $100 \mathrm{U} / \mathrm{ml}$ penicillin, $100 \mu \mathrm{g} / \mathrm{ml}$ streptomycin and amphotericin $250 \mu \mathrm{g} / \mathrm{ml}$. All cultures were maintained at $37^{\circ} \mathrm{C}$ in a humidified atmospheric environment with $5 \% \mathrm{CO}_{2}$ in T162, T75 culture flasks or in six-well plates (for immunofluorescence). Cells were harvested by use of tryp$\sin (0.5 \%$ trypsin-EDTA, Invitrogen), washed once with phosphate-buffered saline (PBS) (Fresensius Kabi Nederland B.V.) and twice with $9 \mathrm{~g} / \mathrm{L} \mathrm{NaCl}$ (Fresensius Kabi Nederland B.V). Passage numbers of the PEX1_1, PEX1_2, PEX1_3, ZS, PEX6, PEX12 and control cell lines were 16-19, 16-20, $13-16,15-20,7-8,19-20$ and 10-20, respectively.

\section{Cell incubations}

Fibroblasts were incubated for different time periods as indicated, with 5,10 or $20 \mathrm{mM}$ of L-arginine monohydrochloride (MERCK, Darmstadt, Germany), $20 \mathrm{mM}$ L-glutamine (MERCK, Darmstadt, Germany) or $543 \mathrm{mM}$ (=50 g/L) glycerol (ACROS Organics, Geel, Belgium) added to the culture medium. Arginine, glutamine and glycerol were dissolved directly in the culture medium and sterilized through a $0.45 \mu \mathrm{m}$ filter (Millipore Millex-HP). Endogenous levels of L-arginine and L-glutamine in the medium was $3 \mathrm{mM}$ and $4.4 \mathrm{mM}$ respectively. Every seven days, the cells were subcultured at a 1:2 dilution and fresh medium was added.

\section{Catalase immunofluorescence (IF) microscopy}

Catalase IF was performed essentially as described previously [15]. Fibroblasts were plated in six-well plates containing ethanol-sterilized cover slips. The next day (when the fibroblasts were attached), the cells were incubated with the different supplements as indicated and prepared for catalase immunofluorescence (IF) microscopy. To determine the effectiveness of the supplementation, the percentage of peroxisome-positive cells (cells with punctate catalase fluorescence) was determined by analyzing at least 200 cells in duplicate. In each experiment the microscope slides were coded to prevent bias. 


\section{Immunoblot analysis}

Fibroblast pellets used for protein analysis, were dissolved in a volume of $200 \mu \mathrm{l}$ of lysis buffer (PBS, 0.25\% Triton X-100, protease inhibitor cocktail tablet (Roche, Mannheim, Germany lot\# 13690100)). Protein samples were sonicated twice (8 watt, 40 Joule) on ice water. Protein concentration was determined by the BCA protein assay according to the manufacturer's (Pierce, Rockford, USA) protocol using human serum albumin (HSA) as standard.

Immunoblot analysis of peroxisomal thiolase was done according to a published method [16].

Immunoblot analysis was performed with homogenates of cultured fibroblasts ( $50 \mu \mathrm{g}$ protein), separated by $10 \%$ SDS-PAGE and transferred onto nitrocellulose by semidry blotting. Antiserum against ACAA1 (thiolase) (SigmaAldrich, St Louis, Missouri, USA) and PEX1 (BD Transduction laboratories, Franklin Lakes, New Jersey, USA) were used at a 1:2000 and 1:250 dilution respectively. As a control for equal protein loading, we simultaneously probed the PEX1 immunoblot with a monoclonal antibody against $\alpha$-tubulin (Sigma-Aldrich, St Louis, Missouri, USA), using a 1:10000 dilution. Antigen-antibody complexes were visualized with IRDye $800 \mathrm{CW}$ goat anti-rabbit secondary antibody for ACAA1, IRDye 800CW goat anti-mouse antibody for PEX1, and IRDye 680RD donkey anti-mouse secondary antibody for tubulin using the Odyssey Infrared Imaging System (LI-COR Biosciences, Nebraska, USA). Quantification of thiolase and PEX1 immunoblots was done using AIDA Image analyzer software (Version 4.26, Raytest, Straubenhardt, Germany), which allows sensitive and reliable quantification of protein amounts in a non-saturated manner.

\section{$\beta$-oxidation of $D_{3}-C 22: 0$ and pristanic acid}

Degradation (to $\mathrm{D}_{3}-\mathrm{C} 16: 0$ ) and elongation (to $\mathrm{D}_{3}-\mathrm{C} 26: 0$ ) of $\mathrm{D}_{3}$-VLCFA in intact cells was measured using $\mathrm{D}_{3}$ C22:0 as substrate [17]. D3-C22:0 (i.e deuterium-labeled free 22,22,22-D3-docosanoic acid) was purchased from CDN Isotopes (Pointe-Claire Canada, lot \#R259AP3).

Assays were performed in duplicate in T75 culture flasks. Medium was replaced by fresh medium supplemented with $\mathrm{D}_{3}-\mathrm{C} 22: 0$ (6 $\mathrm{mM}$ dissolved in DMSO) at a final concentration of $30 \mu \mathrm{M}$. After 72 hours, cells were harvested and VLCFA analysis was done as described before [18]. For determination of protein concentrations, cells were resuspended in $200 \mu$ l deionized water and sonicated for 10 seconds (7 Watt). Pristanic acid $\beta$-oxidation was measured radio chemically according to a published method [19].

\section{Results}

We studied the effect of arginine on peroxisome biogenesis and functioning in primary fibroblasts carrying mild mutations in PEX1, PEX6 or PEX12. As a positive control we used glycerol, which we and others previously found to have a positive effect on these parameters (not shown) [11]. In all cell lines the mutations were found to result in peroxisomal mosaicism when the cells were cultured at $37^{\circ} \mathrm{C}$. As a negative control we used fibroblasts from a ZS patient (homozygous PEX1-I700fsX41), which are completely peroxisome-deficient and as positive control we used three cell lines from unaffected individuals. Initially, we focused on cells with PEX1 mutations, because the PEX1 gene is by far the most commonly affected gene in ZSDs, with the homozygous p.G843D mutation accounting for one-tenth of all PEX1 mutations [8].

\section{Arginine restores peroxisome biogenesis in PEX1-G843D fibroblasts}

We first studied the effect of $50 \mathrm{~g} / \mathrm{L}$ glycerol (positive control [11]) and 5, 10 and $20 \mathrm{mM}$ arginine on the number of cells with catalase-containing peroxisomes (i.e. peroxisome-positive cells) among a total of at least 200 cells (Figure 1). We observed significant increases in the number of peroxisome-positive cells among fibroblasts supplemented with arginine compared to untreated fibroblasts (Figure 1 and Additional file 1: Figure S1). Growth of fibroblasts in the presence of different concentrations of arginine resulted in an increase in the number of peroxisome-positive cells in a concentration-dependent manner.

To exclude a positive effect as consequence of osmotic stress, we also incubated the cells with glutamine, which did not have any effect on the number of peroxisomepositive cells. Supplementation of arginine to the PEX1I700fsX41 cells did not result in peroxisome-positive cells either, whereas in control fibroblasts we observed 100\% peroxisome-positive cells. Because the increase in the number of peroxisome-positive cells when supplemented with $5 \mathrm{mM}$ arginine, was not significant, we omitted this concentration in our further experiments.

In addition to the number of peroxisome-positive cells accessed by catalase fluorescence, we also determined the extent of intraperoxisomal processing of the peroxisomal protein thiolase by immunoblots analysis (Figure 2). The precursor of thiolase, $44 \mathrm{kDa}$, is proteolytically processed in the peroxisome to a mature peptide of $41 \mathrm{kDa}$, as mediated by TYNSD1 [20]. After 7 days of incubation with arginine no increase in the amount of processed $41 \mathrm{kDa}$ thiolase was observed when compared to untreated cells (Figure 2). However, after 14 and 21 days of incubation with arginine or glycerol, an increasing amount of thiolase was found to be processed in the PEX1-G843D cell lines, indicating improved peroxisomal import and protein processing. The addition of arginine resulted in increased levels of processed thiolase $(41 \mathrm{kDa})$ in a concentration and time-dependent manner, while glutamine supplementation showed no effect (Figure 2). 


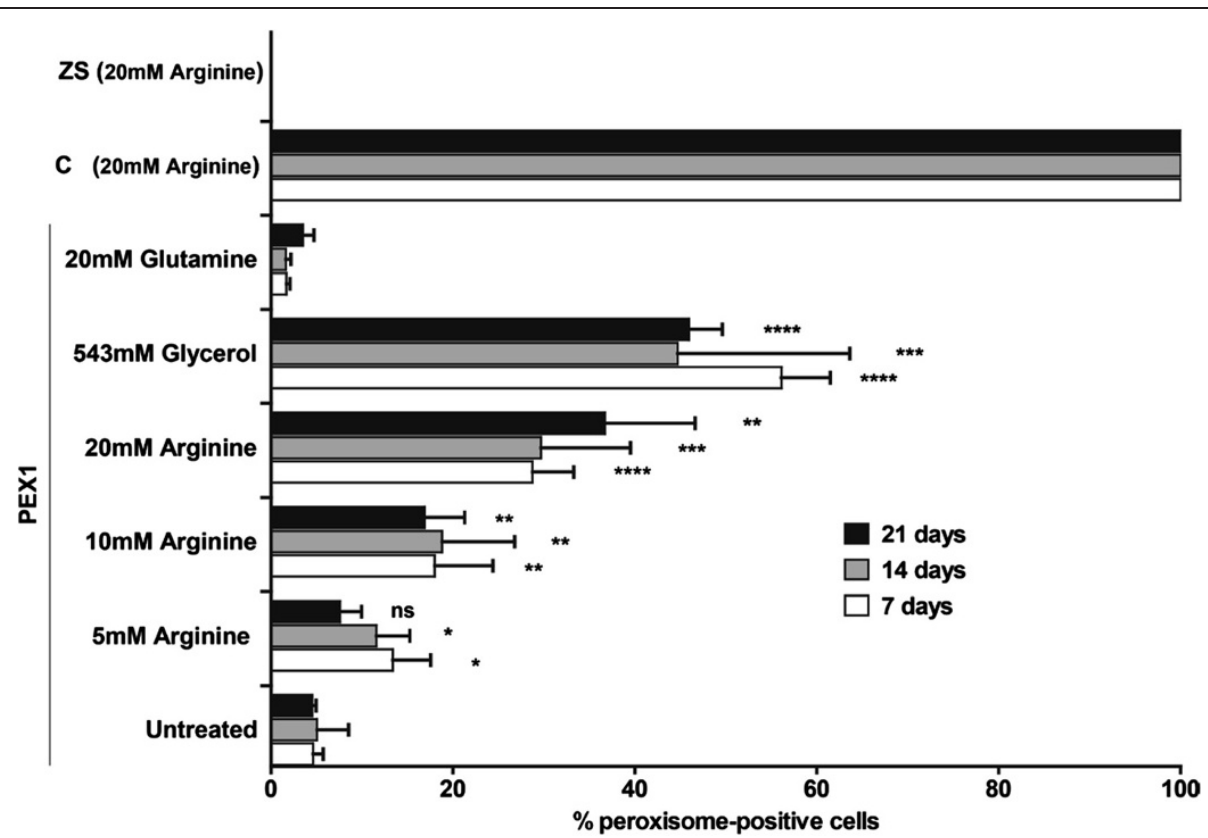

Figure 1 Catalase immunofluorescence of fibroblasts incubated with arginine. PEX1-G843D patient fibroblasts were incubated for 7, 14 or 21 days with different concentrations of arginine, glycerol or glutamine. Glycerol was used as a positive control. In four independent experiments, two cover slips per condition were examined for the number of cells with catalase-containing peroxisomes among at least 200 cells. Data are presented as means $\pm \mathrm{SD}$, statistical analysis was performed with a two-tailed Student's $t$-test, ${ }^{*}, \mathrm{P}<0.05 ;{ }^{* *}, \mathrm{P}<0.005 ;{ }^{* * *}, \mathrm{P}<0.0005 ;{ }^{* * * *}, \mathrm{P}<0.0001$ versus untreated PEX1-G843D fibroblasts. Two additional PEX1-G843D cell lines showed similar results (Additional file 1: Figure S1 and Figure 4). Control (C) showed 100\% peroxisome-positive cells. PEX1-1700fsX41 (negative control = ZS) displayed no peroxisome-positive cells.

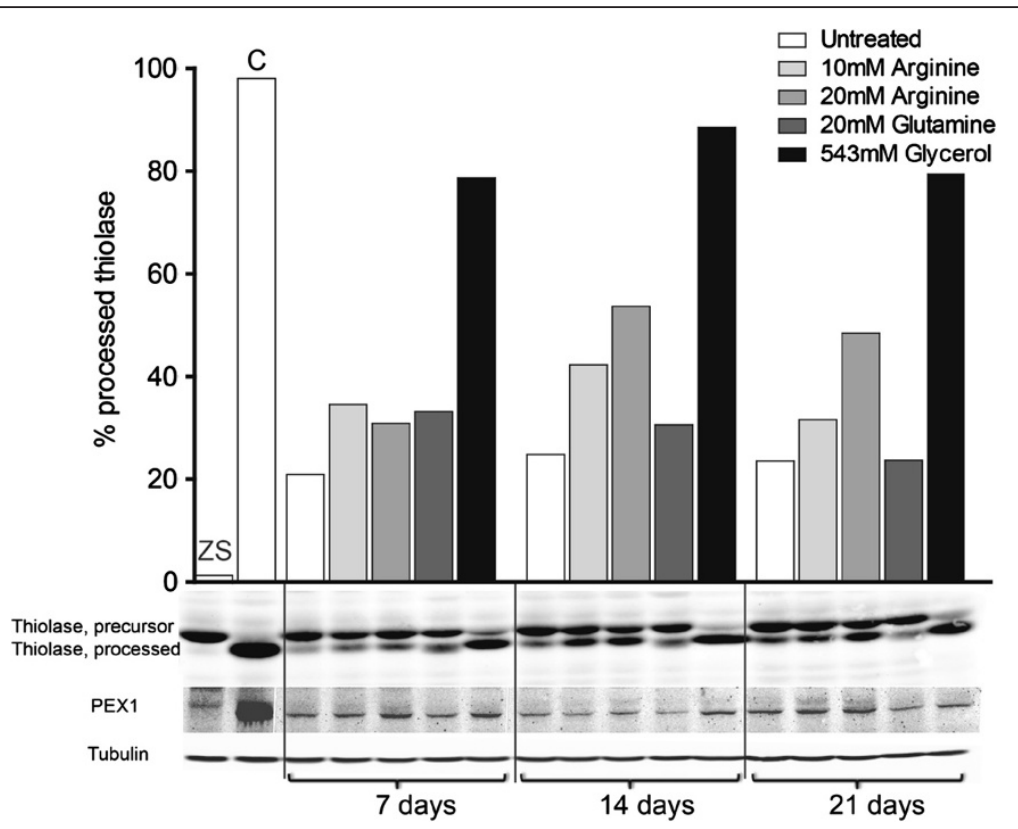

Figure 2 Thiolase and PEX1 immunoblots. The effect of 7, 14 and 21 days incubation of PEX1-G843D cells with arginine, glycerol and glutamine, on the amount of processed $(41 \mathrm{kDa})$ peroxisomal thiolase and PEX1 protein ( $143 \mathrm{kDa})$ was studied by immunoblotting using cell homogenates. The precursor of thiolase, $44 \mathrm{kDa}$, is processed in peroxisomes to a mature peptide of $41 \mathrm{kDa}$. Control showed $98 \%$ processed thiolase, the severe cell line showed 1\% processed thiolase. The faint upper band, seen in the ZS cell line with PEX1 antibody, is aspecific. Tubulin was used to confirm equal protein loading. Data shown are representative of two independent experiments and two additional PEX1-G843D cell lines (data not shown). ZS = severe PEX1-1700fsX41, C = Control. 

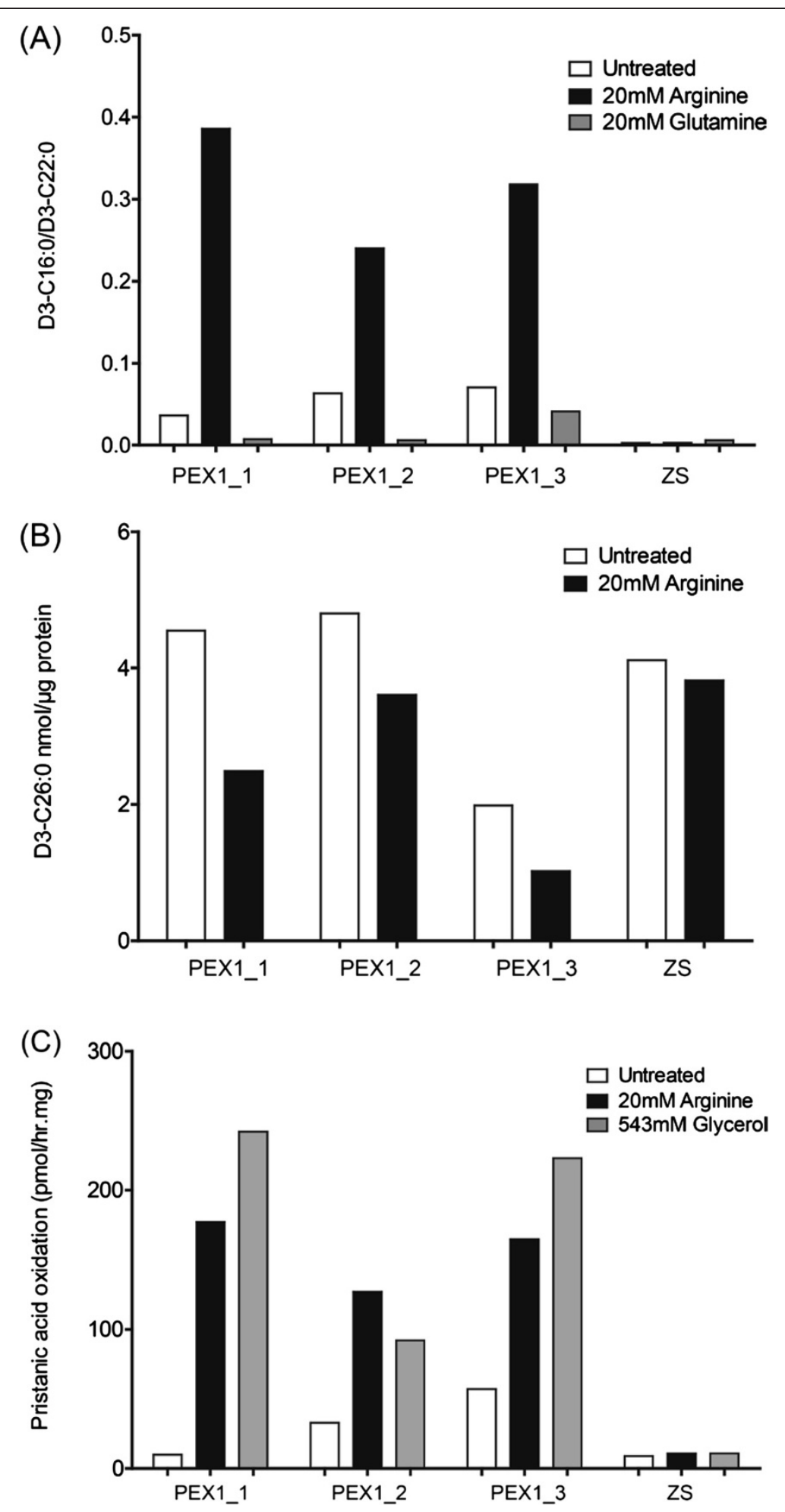

Figure $\mathbf{3}$ (See legend on next page.) 
(See figure on previous page.)

Figure 3 Effect of arginine supplementation on peroxisomal D3-C22:0, pristanic acid $\boldsymbol{\beta}$-oxidation and D3-C22:0 elongation. (A) The D3-C16:0/ D3-C22:0 ratio (degradation) and (B) total amount of D3-C26:0 (elongation) was determined in three independent PEX1-G843D cell lines, incubated for 21 days with arginine. The D3-C16:0/D3-C22:0 ratio and total amount D3-C26:0 in control cells was 2.5 ( \pm 0.5$)$ and 0.2 ( \pm 0.1$) \mathrm{nmol} / \mu \mathrm{g}$ protein, respectively. In fibroblasts from the severe PEX1-I700fsX41 (ZS), the ratio and total amount was $0.002( \pm 0.001)$ and $4.2( \pm 0.1) \mathrm{nmol} / \mu \mathrm{g}$ protein, respectively. (C) The effect of 14 days arginine incubation on the pristanic acid $\beta$-oxidation in three PEX1-G843D cell lines (PEX1_1, PEX1_2 and

PEX1_3). The pristanic acid $\beta$-oxidation in control cells was $544( \pm 182)$ pmol/hr.mg. Statistical analysis was performed with a two-tailed Student's t-test, p-values, when grouped, <0.0001 (figure A), 0.007 (figure B) and 0.006 (figure $\mathbf{C}$ ). Trend in improvement of D3-C22:0 degradation and pristanic acid $\beta$-oxidation is representative for a second independent experiment.

The PEX1-I700fsX41 fibroblasts only showed unprocessed precursor thiolase of $44 \mathrm{kDa}$ under all conditions (data not shown).

Subsequent to thiolase immunoblot analysis we examined the total levels of PEX1 protein by immunoblot analysis, to evaluate if arginine and glycerol supplementation had an effect on the amount of PEX1 (Figure 2). Compared to untreated cells, we observed a minor increase in PEX1 levels in mild PEX1 fibroblasts incubated with $20 \mathrm{mM}$ arginine for 21 days. In cells supplemented with glycerol we already noted an effect after 14 days of incubation. Because the increase in the amount of processed thiolase in cells incubated for 7 days was not significant, we omitted this time point in our further experiments.

\section{Arginine ameliorates the metabolic functions of peroxisomes in PEX1-G843D fibroblasts}

Patients with a mild ZSD have a (partial) deficiency in the degradation of VLCFA ( $\geq$ C22:0) due to a defect in the peroxisomal $\beta$-oxidation, in contrast to $\mathrm{ZS}$ patients in which functional capacity is fully abolished [21]. Therefore, we investigated whether the peroxisomal VLCFA $\beta$-oxidation, i.e. $\beta$-oxidation of $\mathrm{D}_{3}-\mathrm{C} 22: 0$ to $\mathrm{D}_{3}$-C16:0 [17], in the PEX1-G843D cell lines can be restored by addition of arginine and glycerol. It is also known that, due to the defective peroxisomal $\beta$-oxidation, patients with a PBD elongate the accumulating VLCFA (to C26:0) [22]. Hence, we also studied the elongation of $\mathrm{D}_{3}-\mathrm{C} 22: 0$ to $\mathrm{D}_{3}-\mathrm{C} 26: 0$.

Figure $3 \mathrm{~A}$ shows the ratio of $\mathrm{D}_{3}-\mathrm{C} 16: 0 / \mathrm{D}_{3}-\mathrm{C} 22: 0$ (used as an indication for peroxisomal $\beta$-oxidation capacity) in three independent PEX1-G843D cell lines. Incubation with $20 \mathrm{mM}$ arginine resulted in a 4.5 to 10 fold increase in the $\beta$-oxidation of $\mathrm{D}_{3}-\mathrm{C} 22: 0$ in the three PEX1 cell lines, indicating improved peroxisomal functioning. No effect of arginine supplementation on peroxisomal $\beta$ oxidation in control and ZS fibroblasts was observed. Furthermore, incubation with glutamine did not show an effect on the $\beta$-oxidation of $\mathrm{D}_{3}-\mathrm{C} 22: 0$ to $\mathrm{D}_{3}$-C16:0. In addition to an increased peroxisomal $\beta$-oxidation, the arginine supplementation also leads to decreased elongation rates of $\mathrm{D}_{3}-\mathrm{C} 22: 0$ to $\mathrm{D}_{3}-\mathrm{C} 26: 0$ (Figure $3 \mathrm{~B}$ ).
Because ZSD patients also have a (partial) defect in the $\beta$-oxidation of pristanic acid $[23,24]$, we also studied the effect of arginine and glycerol on peroxisomal pristanic acid oxidation. PEX1-G843D cell lines showed a residual pristanic acid $\beta$-oxidation capacity of approximately 10 to $50 \mathrm{pmol} / \mathrm{hr} . \mathrm{mg}$. However, upon arginine incubation, the fibroblasts showed a 3 to 15 fold increase in pristanic acid $\beta$-oxidation capacity (Figure $3 \mathrm{C}$ ). Glycerol caused an even larger increase to approximately 50 to $220 \mathrm{pmol} / \mathrm{hr}$.mg. Fibroblasts from the ZS cell line showed no increase in pristanic acid $\beta$-oxidation when incubated with arginine or glycerol.

\section{Improvement of peroxisomal biogenesis in PEX6 and PEX12 mutant fibroblasts}

Following the positive effects in the PEX1 cell lines, we also investigated the effect of arginine in specific PEX6 and PEX12 cell lines. Both cell lines display peroxisomal mosaicism, with PEX12-p.S320F being the most common PEX12 mutation. This mutation is common in patients from Turkish descent [8]. As observed in the PEX1 cell lines, the addition of $20 \mathrm{mM}$ arginine for 21 days resulted

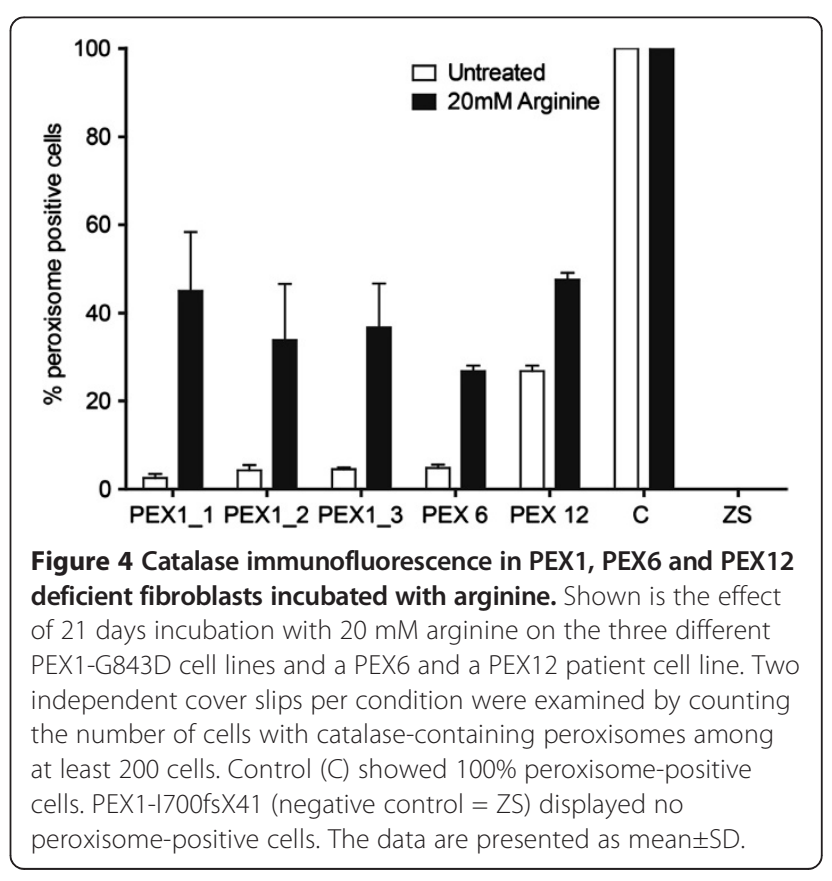


in an increase in the number of peroxisome positive cells (Figure 4) indicating that the effect of arginine is not mutation specific.

\section{Discussion}

Currently, there is no cure for ZSDs and possibilities for supportive and symptomatic treatment are limited. Some patients received docosahexaenoic acid without any proven positive effect [25]. In addition, some patients follow a phytanic acid reduced diet and are supplemented with fat-soluble vitamins [26]. Previous studies revealed a close correlation between the clinical/biochemical severity and the functional consequences of the PEX mutations on the encoded protein in cells from patients with a PBD [27]. Among the reported mutations in the PEX1 gene, which is most commonly defective, the PEX1-G834D mutation is associated with a mild clinical phenotype and relatively mild biochemical and cellular abnormalities [27-30].

In the present study, we investigated the effect of arginine and glycerol on peroxisome biogenesis and functioning in a subset of specific PEX1, PEX6 or PEX12-defective fibroblasts, that all display peroxisomal mosaicism. Previous studies have shown that these cell lines showed improved peroxisomal function, when cultured at $30^{\circ} \mathrm{C}$, suggesting a problem in protein folding. Furthermore Zhang et al., 2010 [11] observed a positive effect of several compounds on peroxisomal function in cell lines with the PEX1-G834D mutation. To study whether the presumed protein folding problem can be improved, we incubated these cell lines with arginine or glycerol, two known chemical chaperones in vitro [12].

Our results show a significant increase in the amount of peroxisome-positive cells, the intraperoxisomal processing of thiolase, the $\beta$-oxidation of $\mathrm{D}_{3}-\mathrm{C} 22: 0$ (to $\mathrm{D}_{3}$-C16:0) and pristanic acid and a decrease in the elongation of $\mathrm{D}_{3}$-C22:0 (to $\mathrm{D}_{3}$-C26:0) in homozygous PEX1-G843D fibroblasts incubated with arginine. The mild untreated PEX1 cell lines showed similar values of $\mathrm{D}_{3}$-C26:0 compared to the ZS cell line. This implies that untreated mild PEX1 cell lines are not sufficiently metabolic active to rescue the elongation of $\mathrm{D}_{3}$-C22:0 to $\mathrm{D}_{3}$-C26:0. However, upon arginine supplementation, we observed decreased levels of $\mathrm{D}_{3}$-C26:0 levels. Furthermore, we found a positive effect of arginine on the amount of peroxisome-positive cells in specific PEX6 and PEX12 cell lines.

Despite the apparent improvement in peroxisome biogenesis and functioning, we only found a small increase in the amount of PEX1 protein upon immunoblot analysis of cell homogenates incubated for 21 days with $20 \mathrm{mM}$ arginine. Apparently, the improvement in peroxisomal function is not accompanied by an obvious increase in total amount of PEX1 protein. Unfortunately, with immunoblot analysis, we cannot discriminate between incorrectly and correctly folded PEX1 protein, but we assume that arginine results in higher levels of correctly folded PEX1G843D protein.

Osmotic stress can induce heat shock proteins, which enhance improved protein folding [31]. To exclude that the improvement of arginine was due to such an osmotic stress effect, we incubated the cells with comparable concentrations of glutamine. Glutamine is also an amino acid, but has no known chaperone properties. Overall, we did not observe any effect on peroxisome biogenesis and functioning upon glutamine supplementation.

\section{Conclusion}

Although incubation with glycerol showed a more potent effect than arginine, the concentration used to reach this effect is too high (i.e. $543 \mathrm{mM}$ ) for potential clinical application. However, because plasma arginine concentrations can reach levels from up to $6 \mathrm{mM}$ in humans and arginine supplementation is given to other diseases, including MELAS-syndrome [32], for which few side-effect are reported, we believe that arginine supplementation may provide a potential therapy for mild ZSD patients. In MELAS syndrome, arginine is thought to function as a nitric oxide stimulator rather than a chemical chaperone. It has been suggested that arginine activates the production of nitric oxide and thereby the induction of stress and upregulation of heat shock proteins [33]. It is possible that also in our study arginine activates this nitric oxide-mediated pathway and induces the expression of heat shock proteins to improve folding. This will be addressed in future studies.

Finally, given the fact that peroxisomal disorders are neurological diseases it is interesting to note that arginine can cross the blood-brain-barrier [34].

\section{Additional file}

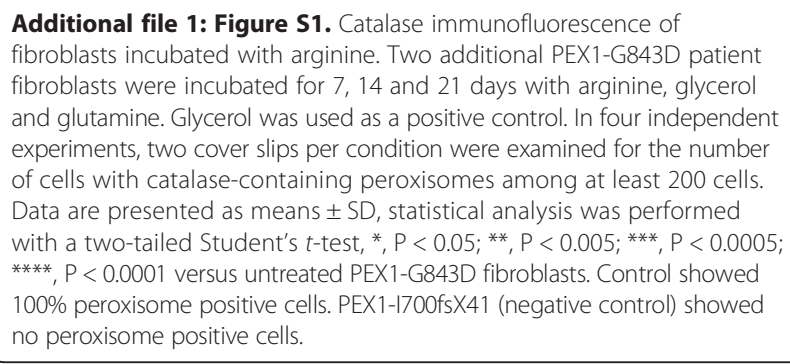

\section{Abbreviations}

$\mathrm{D}_{3}$ : Deuterium-labeled; $\mathrm{D}_{3}$-C22:0: Deuterium-labeled free 22,22,22-D3docosanoic acid; DMEM: Dulbecco's Modified Eagle's Medium; IRD: Infantile refsum disease; MELAS: Mitochondrial encephalomyopathy lactic acidosis and stroke-like episodes; NALD: Neonatal adrenoleukodystrophy; PBD: Peroxisome biogenesis disorder; VLCFA: Very long chain fatty acids; ZSD: Zellweger spectrum disorder; ZS: Zellweger syndrome. 


\section{Competing interests}

The authors declare that they have no competing interests.

\section{Authors' contributions}

KB, MSE, LIJ: Conception and design, data acquisition, analysis, interpretation, manuscript draft and revision. BTPT, RJAW: conception and design, manuscript draft and revision. HRW: data interpretation, conception and design, manuscript draft and revision. All authors read and approved the final manuscript.

\section{Acknowledgements}

We thank Stephan Kemp, Petra Mooijer and Inge Dijkstra for their contributions. This work was supported by grants from foundation "Stichting Steun Emma" and "Metakids", Amsterdam, the Netherlands.

\section{Author details}

'Department of Clinical Chemistry, Laboratory Genetic Metabolic Diseases, Academic Medical Center, University Hospital of Amsterdam, Meibergdreef 9, 1105 AZ Amsterdam, The Netherlands. ²Department of Pediatric Neurology, Emma Children's Hospital, Academic Medical Center, University Hospital of Amsterdam, Meibergdreef 9, 1105 AZ Amsterdam, The Netherlands.

Received: 28 June 2013 Accepted: 30 August 2013

Published: 9 September 2013

\section{References}

1. Wanders RJA, Waterham HR: Biochemistry of mammalian peroxisomes revisited. Annu Rev Biochem 2006, 75:295-332.

2. Kelley RI, Datta NS, Dobyns WB, Hajra AK, Moser AB, Noetzel MJ, Zackai EH, Moser HW: Neonatal adrenoleukodystrophy: new cases, biochemical studies, and differentiation from Zellweger and related peroxisomal polydystrophy syndromes. Am J Med Genet 1986, 23:869-901.

3. Poll-The BT, Saudubray JM, Ogier H a, Odièvre M, Scotto JM, Monnens L, Govaerts LC, Roels F, Cornelis a, Schutgens RB: Infantile Refsum disease: an inherited peroxisomal disorder. Comparison with Zellweger syndrome and neonatal adrenoleukodystrophy. Eur J Pediatr 1987, 146:477-483.

4. Steinberg SJ, Elçioglu N, Slade CM, Sankaralingam A, Dennis N, Mohammed SN, Fensom AH: Peroxisomal disorders: clinical and biochemical studies in 15 children and prenatal diagnosis in 7 families. Am J Med Genet 1999, 85:502-510

5. Gootjes J, Schmohl F, Mooijer P a W, Dekker C, Mandel H, Topcu M, Huemer M, Von Schütz M, Marquardt T, Smeitink J a, Waterham HR, Wanders RJA: Identification of the molecular defect in patients with peroxisomal mosaicism using a novel method involving culturing of cells at 40 degrees C: implications for other inborn errors of metabolism. Hum Mutat 2004, 24:130-139.

6. Imamura A, Tamura S, Shimozawa N, Suzuki Y, Zhang Z, Tsukamoto T, Orii T, Kondo N, Osumi T, Fujiki Y: Temperature-sensitive mutation in PEX1 moderates the phenotypes of peroxisome deficiency disorders. Hum Mol Genet 1998, 7:2089-2094.

7. Shimozawa N, Suzuki Y, Zhang Z, Imamura a, Toyama R, Mukai S, Fujiki Y, Tsukamoto T, Osumi T, Orii T, Wanders RJA, Kondo N: Nonsense and temperature-sensitive mutations in PEX13 are the cause of complementation group $\mathrm{H}$ of peroxisome biogenesis disorders. Hum $\mathrm{Mol}$ Genet 1999, 8:1077-1083.

8. Ebberink MS, Mooijer P a W, Gootjes J, Koster J, Wanders RJA, Waterham HR: Genetic classification and mutational spectrum of more than 600 patients with a Zellweger syndrome spectrum disorder. Hum Mutat 2011, 32:59-69.

9. Steinberg S, Chen L, Wei L, Moser A, Moser H, Cutting G, Braverman N: The PEX Gene Screen: molecular diagnosis of peroxisome biogenesis disorders in the Zellweger syndrome spectrum. Mol Genet Metab 2004, 83:252-263.

10. Waterham HR, Ebberink MS: Genetics and molecular basis of human peroxisome biogenesis disorders. Biochimica et Biophysica Acta (BBA) Molecular Basis of Disease 2012, 1822:1430-1441.

11. Zhang $R$, Chen $L$, Jiralerspong S, Snowden A, Steinberg S, Braverman N: Recovery of PEX1-Gly843Asp peroxisome dysfunction by small-molecule compounds. Proc Natl Acad Sci U S A 2010, 107:5569-5574.

12. De Bernardez Clark E, Schwarz E, Rudolph R: Inhibition of aggregation side reactions during in vitro protein folding. Methods in enzymology 1999, 309:217-236.
13. João Silva M, Pinheiro A, Eusébio F, Gaspar A, Tavares de Almeida I, Rivera I: Pyruvate dehydrogenase deficiency: identification of a novel mutation in the PDHA1 gene which responds to amino acid supplementation. Eur J Pediatr 2009, 168:17-22.

14. Perlmutter DH: Chemical chaperones: a pharmacological strategy for disorders of protein folding and trafficking. Pediatr Res 2002, 52:832-836.

15. Wanders RJ, Wiemer EA, Brul S, Schutgens RB, Van den Bosch H, Tager JM: Prenatal diagnosis of Zellweger syndrome by direct visualization of peroxisomes in chorionic villus fibroblasts by immunofluorescence microscopy. J Inherit Metab Dis 1989, 12(Suppl 2):301-304.

16. Wanders RJ, Dekker C, Ofman R, Schutgens RB, Mooijer P: Immunoblot analysis of peroxisomal proteins in liver and fibroblasts from patients. J Inherit Metab Dis 1995, 18(Suppl 1):101-112.

17. Kemp S, Valianpour F, Mooyer PAW, Kulik W, Wanders RJA: Method for measurement of peroxisomal very-long-chain fatty acid beta-oxidation in human skin fibroblasts using stable-isotope-labeled tetracosanoic acid. Clin Chem 2004, 50:1824-1826.

18. Valianpour F, Selhorst JJ, Van Lint LE, Van Gennip AH, Wanders RJ, Kemp S: Analysis of very long-chain fatty acids using electrospray ionization mass spectrometry. Mol Genet Metab 2003, 79:189-196.

19. Wanders RJA, Denis S, Ruiter JP, Schutgens RB, Van Roermund CW, Jacobs BS: Measurement of peroxisomal fatty acid beta-oxidation in cultured human skin fibroblasts. J Inherit Metab Dis 1995, 18(Suppl 1):113-124.

20. Kurochkin IV, Mizuno Y, Konagaya A, Sakaki Y, Schönbach C, Okazaki Y: Novel peroxisomal protease Tysnd1 processes PTS1- and PTS2-containing enzymes involved in beta-oxidation of fatty acids. EMBO J 2007, 26:835-845.

21. Schutgens RB, Bouman IW, Nijenhuis a a, Wanders RJ, Frumau ME: Profiles of very-long-chain fatty acids in plasma, fibroblasts, and blood cells in Zellweger syndrome, X-linked adrenoleukodystrophy, and rhizomelic chondrodysplasia punctata. Clin Chem 1993, 39:1632-1637.

22. Kelley Rl: Review: the cerebrohepatorenal syndrome of Zellweger, morphologic and metabolic aspects. Am J Med Genet 1983, 16:503-517.

23. Poulos A, Sharp P, Fellenberg AJ, Johnson DW: Accumulation of pristanic acid $(2,6,10,14$ tetramethylpentadecanoic acid) in the plasma of patients with generalised peroxisomal dysfunction. Eur J Pediatr 1988, 147:143-147.

24. Singh $H$, Usher $\mathrm{S}$, Johnson D, Poulos a: A comparative study of straight chain and branched chain fatty acid oxidation in skin fibroblasts from patients with peroxisomal disorders. J Lipid Res 1990, 31:217-225.

25. Paker a M, Sunness JS, Brereton NH, Speedie LJ, Albanna L, Dharmaraj S, Moser a B, Jones RO, Raymond GV: Docosahexaenoic acid therapy in peroxisomal diseases: results of a double-blind, randomized trial. Neurol 2010, 75:826-830.

26. Poll-The BT, Engelen M: Peroxisomal leukoencephalopathy. Semin Neurol 2012, 32:42-50.

27. Weller S, Gould SJ, Valle D: Peroxisome biogenesis disorders. Annu Rev Genomics Hum Genet 2003, 4:165-211.

28. Rosewich $\mathrm{H}$, Ohlenbusch a, Gärtner J: Genetic and clinical aspects of Zellweger spectrum patients with PEX1 mutations. J Med Genet 2005, 42:e58.

29. Gärtner J, Preuss N, Brosius U, Biermanns M: Mutations in PEX1 in peroxisome biogenesis disorders: G843D and a mild clinical phenotype. J Inherit Metab Dis 1999, 22:311-313.

30. Preuss N, Brosius UTE, Biermanns M, Muntau AC, Conzelmann E, Gärtner J: PEX1 Mutations in complementation group 1 of Zellweger spectrum patients correlate with severity of disease. Pediatr Res 2002, 51:706-714.

31. Samali A, Orrenius S: Heat shock proteins: regulators of stress response and apoptosis. Cell Stress Chaperones 1998, 3:228-236.

32. Koga Y, Akita Y, Nishioka J, Yatsuga S, Povalko N, Katayama K, Matsuishi T: MELAS and L-arginine therapy. Mitochondrion 2007, 7:133-139.

33. $X u$ Q, Hu Y, Kleindienst R, Wick G: Nitric oxide induces heat-shock protein 70 expression in vascular smooth muscle cells via activation of heat shock factor 1. J Clin Invest 1997, 100:1089-1097.

34. Oldendorf $\mathrm{WH}$, Szabo J: Amino barrier acid assignment to one of three blood-brain amino acid carriers. Am J Physiol 1976, 230:94-98.

doi:10.1186/1750-1172-8-138

Cite this article as: Berendse et al: Arginine improves peroxisome functioning in cells from patients with a mild peroxisome biogenesis disorder. Orphanet Journal of Rare Diseases 2013 8:138. 